Zdenka ̌̌ADL*

\title{
EMOCIJE IN AFEKT V POLITIČNEM DISKURZU**
}

Povzetek. Včlanku se ukvarjamo s sodobno obliko emocionalne politične komunikacije, posebej nas zanima populizem kot oblika politike, ki na ljudi apelira primarno na emocionalni ravni. Opozorimo na problematičnost emocionalizacije populističnih diskurzov, ki se kaže v legitimizaciji agresivne retorike, manipuliranju emocij, emotivizmu in ustvarjanju antagonističnih kolektivov. Na podlagi kritične ocene, da razumevanje političnosti emocij zahteva sistematično teoretizacijo emocij, se $v$ zadnjem delu opremo na konceptualni okvir avtorice Sare Ahmed, s pomočjo katerega prikažemo performativno vlogo emocij in njihovo "lepljivost", zlasti souražnih emocij. Analiza pokaže, da teorija premikajočih se in "lepljivih" emocij ter afektov omogoča boljše razumevanje vloge emocij v političnem diskurzu, zlasti desnega populizma.

Ključni pojmi: politična komunikacija, politični diskurz, emocije, sovraštvo, populizem, Sara Ahmed

\section{Uvod}

Politično polje $\mathrm{v}$ kontekstu neoliberalne globalizacije, politične in ekonomske destabilizacije ter migracij zaznamujejo nacionalizmi, ksenofobija, populistični diskurz in postresničnost. $\mathrm{V}$ teh okoliščinah politike ni mogoče misliti brez emocij in njihovih političnih učinkov v družbenih praksah. Živimo v »dobi emocionalne politike« (Heaney, 2019: 1), v kateri so »odkrit[e] emocij[e] ne le vse bolj sprejemljiv[e], ampak, kot se zdi, potrebn[e] v sodobni politiki« (Irvine, 2007: 2). Politika postaja vse bolj»emocionalizirana" (Scherer, 2002 v Sonntag, 2011: 124; Frevert, 2019; Richards, 2004), emocije so postale osrednje v dinamiki politične deliberacije (npr. Hall, 2007) in imajo »omniprezentno vlogo v svetovni politiki« (Bleiker in Hutchison, 2008: 115). Vsenavzočnost emocij je v mediatiziranem političnem kontekstu več kot očitna. Jeza, strah, gnev, sovraštvo, sočutje, ljubezen, empatija in upanje so osrednji motivi politične komunikacije in kliučna

* Dr. Zdenka Šadl, izredna profesorica, Fakulteta za družbene vede, Univerza v Ljubljani, Slovenija.

** Izvirni znanstveni članek. DOI: $10.51936 /$ tip.58.2.370-390 
sredstva, ki jih v mobilizaciji podpore ter zbujanju medijske pozornosti uporabljajo populistični in mainstream politični akterji iz celotnega političnega spektra. Emocije so »osrednjega pomena za celotno politiko, vključno z vladami in mainstream strankami« (Ost, 2004: 240).

Emocionalizacija politike, ki jo v članku razumemo kot diskurzivno retorično strategijo, ki uporablja in razširja emocije (patos) za prepričevalne namene, (pre)usmerjanje političnih stališč, odločitev in vedenja, je posebna specifika populizma. Sodobni populizem opazujemo kot političen slog, ki ga politični akterji uprizarjajo $\mathrm{v}$ različnih kulturnih in političnih kontekstih (Moffitt, 2016). ${ }^{1}$ Moffitt (2016: 77) se pri konceptualizaciji populizma kot političnega sloga opre na trditev, da je v mediatizirani politični tekmi slog pomembnejši od načel, stranke in policy. Populističen slog označujejo tri značilnosti: apeliranje na ljudstvo nasproti elitam, slabe manire in diskurzivna konstrukcija krize (Moffitt, 2016: 45). ${ }^{2}$ Politični slog se kaže skozi retoriko - uporabo retoričnih apelov (etos, logos, patos), s katerimi želijo politiki okrepiti prepričljivost svojih argumentov. Čeprav populistični politiki nimajo monopola nad retoričnimi emocionalnimi apeli, kaže populizem specifično nagnenje $\mathrm{k}$ uporabi patosa. $\mathrm{V}$ desnem populizmu, na katerega se v članku osredinjamo, se uporaba diskurza emocij kaže v značilnem slogu politične komunikacije: $v$ poudarjeno provokativnem, sramotilnem, očitajočem, predvsem pa v konfrontirajočem in jeznem načinu govorice ter $\mathrm{v}$ mobiliziranju negativnih emocij proti »elitam« (ter migrantom, istospolno usmerjenim, prejemnikom socialne pomoči itd.), ki »ogrožajo blaginjo »judstva«, varnost in družbeni red. Več kot zgled populističnega sloga je Trumpov »jezni populizem« (Wahl-Jorgensen, 2019). Trumpova retorika je z izkoriščanjem negativnih emocionalnih refleksov na učinke neoliberalne globalizacije in diskurzivno konstrukcijo sovražnikov ustvarjala antagonistično razmerje "mi-oni« ter polarizirala politični in celoten družbeni prostor. Zmaga Trumpa na predsedniških volitvah leta 2016 je bila pomemben mejnik v širjenju »jezne sovražnosti« tako v ZDA kot v Evropi. V slovenskem prostoru je politično mobiliziranje nestrpnosti $\mathrm{v}$ desnem političnem taboru (npr. Dragoš, 2004; Mekina, 2004), reproducirano z mediji (npr. Pušnik, 2017), že dolgo stalnica. V trenutnih razmerah se najbolj odmevno manifestira $\mathrm{v}$ jeznih in provokativnih izjavah in tvitih aktualnega premierja Janeza Janše, zlasti v njegovih napadih na novinarsko kritiko. Z množico diskurzov v javni, medijski domeni (politični govori, spletna mesta, časopisni članki)

1 Populizem pa ni zgolj političen slog oz. slog politične komunikacije, razumemo ga tudi kot slabo utemeljeno ali "tanko" ideologijo (thin-centred ideology), ki na osnovi normativnih idej in vrednot omogoča osmislitev sveta, ki ga prikazuje.

2 Po drugi strani t.i. »tehnokratski slog«združuje apeliranje na ekspertizo, lepe manire in zgodbo o stabilnosti ali napredku (Moffitt, 2016: 26, 44). 
krožijo tudi emocije in afekti, ${ }^{3}$ ki igrajo pomembno vlogo v oblikovanju političnih stališč, identitete in kolektivov. Izhajajoč iz predpostavke, da so politični diskurzi v osnovi usmerjeni na način čutenja, se v članku ukvarjamo s performativnostjo političnih diskurzov iz emocionalne perspektive (diskurzivno konstrukcijo emocij) in performativnostjo emocij (delovanjem in družbenimi učinki emocij, njihovo politično naravo).

Emocionalni naboj političnega jezika ni noviteta, ampak kontinuiteta. Politiki - poleg predstavljanja racionalnih argumentov - občinstvo vselej nagovarjajo tudi na emocionalni ravni. Emocije niso zgolj pojavi, ki izražajo dejanske telesne procese, temveč performirajo določene družbene pomene, prepričanja, stališča in jih organizirajo v (politično) delovanje. Kot ugotavljajo Goodwin in drugi (2001), so emocije močne motivacijske sile za politično participacijo in mobilizacijo, kar pojasnjuje njihovo nepogrešljivost $\mathrm{v}$ političnih tehnologijah vodenja sleherne družbe. Politični jezik vselej niha med mešanicami strategij prepričevanja (logosa, patosa in etosa), pomembnost emocij za prepričljivost diskurza pa je pri-po-znana že od Aristotela dalje. Čeprav gre za zgodovinsko stalnost, se stil in vsebina emocionalne politične komunikacije navezujeta na vsakokraten družbeno-kulturni kontekst ter zgodovinsko variabilne oblike emocionalnih izkustev.

V svoji trenutni obliki se emocionalizacija politične komunikacije kaže kot rezultat procesov, ki se od poznih šestdesetih let 20. stoletja dalje odvijajo v evropskem in ameriškem prostoru, in sicer: terapevtske kulture in procesa emocionalizacije družbe (McCharty, 1989; Wounters, 1986; Furedi, 2003), ki sta spodbudila korenit premik k refleksivnemu ukvarjanju z emocijami, podelila legitimnost občutenju (ekpresiji) različnih emocij v zasebni in javni sferi ter vodila $\mathrm{k}$ brisanju meja med zasebno emocijo in javno komunikacijo; razvoja množičnih medijev, ki so utrdili z modernizacijskimi učinki pogojeno personalizacijo politike in personalno politično retoriko, posebej razvoja televizije, ki primarno vzbuja emocionalne (in ne kognitivne) odnose med gledalcem in govorcem (Hoggett, 2009: 54-55), ter emocionalizacije celotnih televizijskih programov (Bassols et al., 2013); spreminjajočega političnega okolja, ki zahteva ustvarjanje emocionalno privlačnih naracij, prilagojenih okusu "potrošnikov« in prevzemanje »emocionalno usmerjenih tehnik marketinga in oglaševanja» (Richards, 2004: 340;

3 V literaturi glede konceptov ni soglasja, nekateri ju razlikujejo, drugi to razlikovanje zavračajo, njune razlike pa so različno opredeljene. Posplošeno vzeto lahko rečemo, da "emocije označujejo kogni-

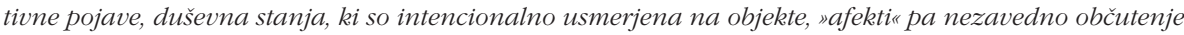
('intenzivnost') $v$ telesu. Afekti so trdneje biološko in fiziološko določeni, nekognitivni in manj usidrani $v$ diskurz, zato bolj fluidni in manj predvidljivi. Ahmed (2004: 40) je kritična do čezmerno polariziranega modela občutenja, ki emocije razlikuje od afektov. V članku ju razumemo kot relacijska koncepta, ki označujeta intersubjektivna izkustva in njihovo performativno vlogo v oblikovanju identitet, kolektivov in pripadnosti skozi diskurz (Westberg, 2021: 24). 
Hoggett, 2009: 54-55); mediatizacije politične komunikacije, ki preferira in promovira tiste vidike politike, ki so dovolj senzacionalistični, da pritegnejo pozornost občinstva (Sonntag, 2011: 124); in nenazadnje, razvoja digitalnih tehnologij in novih kanalov komuniciranja, zlasti uporabe družbenih medijev (t.i. »emocionalnih medijev«), ki so še posebej primerni za neposreden, takojšen, angažiran in emocionaliziran slog komunikacije (Ernst et al., 2017; Tettegah, 2016; Breeze, 2020; Wahl-Jorgensen, 2019). V kontekstu prepleta različnih procesov, ki jo oblikujejo, postaja emocionalna politična komunikacija bolj poudarjena in intenzivnejša kot kdajkoli prej. To še posebej velja za obdobje po 11. septembru, ko postanejo emocije močno politizirane in vpete v politiko strahu in gnusa (Ahmed, 2004a, 2004b), emocionalizacijo "vojne proti terorizmu (Ahmed, 2015) in "nacionalno sentimentalno politiko (moške) zaščite" (Bargetz, 2015: 580). Ali kot je to v svojem govoru kongresu izjavil George W. Bush (2001) sam: »[...] Naša žalost se je spremenila $\mathrm{v}$ jezo in jeza $\mathrm{v}$ resolucijo [...] Velika škoda nam je bila storjena. Utrpeli smo veliko izgubo. In v svoji žalosti in jezi smo našli svoje poslanstvo in svoj trenutek."

Intenziteta, s katero populistični politiki posvajajo emocionalno retoriko, reaktualizira staro zanimanje za emocije v politiki, odpira pa tudi vprašanje teoretizacije emocij, ki je pri tem pogosto umanjkala. Članek začenjamo z nerazdružljivo usodo politike in emocij, racionalistično koncepcijo politike in novimi pristopi, ki postavljajo emocije $\mathrm{v}$ središče političnih analiz. Nadaljujemo z obravnavo emocionalne dimenzije političnih diskurzov, posebej emocionalnega diskurza desnega populizma in politizacijo emocij v njem. Zatem se preusmerimo k vprašanju političnosti samih emocij. Kaj dela emocije politične oz. kakšno konceptualizacijo emocij potrebujemo za razumevanje njihove vloge v konstrukciji identitet in kolektivnih teles? Schrock in drugi (2017: 6) ugotavljajo, da se preučevanje emocij v politiki pogosto opira na razumevanje emocij kot notranjih stanj in individualnih samoizražanj. ${ }^{4}$ Zgolj psihološko razumevanje emocij pa ne pojasni zadovoljivo logike delovanja (kolektivnih) emocij. Vprašanje, kako emocije delujejo $\mathrm{v}$ procesih ustvarjanja kolektivov, zahteva teoretizacijo in koncepte, ki, prvič, pomikajo razumevanje emocij od psiholoških modelov naprej v smeri njihove odnosnosti, performativnosti in kolektivnega značaja in drugič, raziskujejo kompleksne intersekcije med družbenimi in kulturnimi dejavniki, diskurzivnimi praksami ter individualno izkušanimi, a zgodovinsko in kulturno situiranimi emocijami. Pri obravnavi teh vprašanj se bomo oprli na konceptualni okvir Sare Ahmed (2004a; 2004b). Zastavljamo si dve glavni raziskovalni vprašanji: Kakšna je vloga emocij v političnih diskurzih

4 Schrock et al. (2017: 6) še opozarjajo, da je diskurzivna produkcija emocij, kljub stalnim pozivom po raziskovanju emocij v politiki v sociologiji, še vedno premalo raziskana. 
populizma? Kako nam lahko teorija emocij S. Ahmed pomaga pri razlagi vloge emocij v političnem diskurzu? Naš teoretični in metodološki pristop temelji na kombinaciji obstoječih teoretizacij in raziskav o emocionalnem stilu komuniciranja desnih političnih akterjev s teorijami emocij v družbenih vedah, ki temeljijo na konstrukcionističnem pristopu.

\section{Konceptualizacija politike: od izključitve k vključitvi emocij}

Pri razumevanju zveze politika/politično-emocije je treba emocije obravnavati kot »utelešene misli« (Rosaldo, 1984). Emocije niso zgolj telesni, temveč tudi kognitivni (evaluativni) procesi, ki vsebujejo vrednostne (moralne) sodbe (npr. Izard, 2007; Feigenson, 2003), s katerimi subjekti izražajo svoje potrebe, želje, cilje in ideale. Telesno vznemirjenje, ki spremlja presoje in ocene objektov v danem kontekstu, pripravi subjekt za delovanje. Emocije "niso le del naših odzivov na dogodke, ampak - v obliki globokih afektivnih predanosti - oblikujejo tudi cilje naših delovanj« (Jasper, 1998: 398). Emocije odražajo naš odnos do sveta; njihovo čutenje in izražanje kažeta, kaj je za nas pomembno, kaj vpliva na nas, kako ocenjujemo stvari, druge, situacije. Kot take igrajo »vlogo v presojanju o dobrem in pravičnem ter zato 374 v ocenah političnih idej in idealov« (Burkitt, 2005, v Linjakumpu, 2007: 4). Emocije utrjujejo in spreminjajo naša zaznavanja in prepričanja (Frijda et al., 2000) oz. imajo moč, da (pre)usmerjajo, polarizirajo in intenzivirajo naša politična stališča.

Vgrajene v komunikacijo in interakcijo so emocije osrednjega pomena za družbeno delovanje (Barbalet, 1998) in vse družbene odnose, torej so sestavina normalnega delovanja družbe in politike. Polje "političnega«, $v$ katerem se po Szanto in Slaby (2020: 478) "pogajamo o naši pluralnosti in razlikah z namenom svobode, moči, individualne avtonomije, kolektivnega priznanja ali naših oblik sobivanja«, je bistveno afektivne narave. Ukvarja se s stvarmi, ki so

nam pomembne, si jih želimo ali nas navdajajo s strahom, s stvarmi, ki nas zadevajo - nas kot skupnost. Velja tudi obratno, afektivno je vselej politično. Emocije niso zgolj subjektivni pojavi, ampak jih urejajo "pravila čustvovanja" (Hochschild, 1983) in uravnavajo skupne ali konfliktne vrednote. Torej, emocije vselej vključujejo pogajanja o tem, kaj, kako in skupaj s kom (ali proti komu) bi morali občutiti. (Szanto in Slaby, 2020: 478, poud. v orig.)

Čeprav so politično relevantnost emocij $\mathrm{v}$ analizi retorike prepoznali že antični filozofi, so politični filozofi emocije v svojih analizah pogosto spregledali ali marginalizirali. V osrčju izključevanja emocij iz politike in 
politične analize je ležala tiha predpostavka o dihotomiji emocij/strasti in razuma. Vpeta v teorije, jezik in zaznave je določala mesto emocijam tako v družbenih in političnih vedah kot tudi $\mathrm{v}$ družbi in politiki. V politiki so bile opredeljene kot muhaste in neukrotljive sile, $\mathrm{v}$ najboljšem primeru so veljale kot irelevantne, $v$ najslabšem pa kot ovira pri doseganju nepristranskih presoj, nujnih za izvajanje pravilnih odločitev in učinkovitih politik (Hutchison, 2018). Prevlada dualističnega diskurza je emocije za dolga desetletja potisnila na rob politične teorije, političnih ved in politične sociologije.

Nov val zanimanja za emocije in afektivnost je sprožil t.i. emocionalni obrat, kasneje tudi afektivni obrat (Clough in Halley, 2007) v sredini devetdesetih let 20. st. Nova epistemologija $\mathrm{v}$ družbenih in političnih vedah je emocije povezala z družbenimi, kulturnimi in političnimi normami ter kritično izzvala zgodovinsko dihotomijo razum/emocije ter fetišizem razuma v racionalistični koncepciji politike. Dandanes je proučevanje emocij v politiki eno najbolj propulzivnih področij političnih ved in politične sociologije, zlasti na področju proučevanja narave družbenih vezi in družbene kohezije ter politične komunikacije (npr. Hoggett, 2009; Engelken-Jorge idr., 2011).

\section{Emocionalno-diskurzivne prakse $\mathrm{v}$ političnem komuniciranju}

Emocionalizacija politike se kaže tako v vsakdanji uporabi emocionalnega jezika znotraj rutinske politike $\mathrm{v}$ parlamentih in političnih strankah, kot tudi v dramatični emocionalni retoriki volilne politike in predsedniški retoriki. Primerov prepričevanja prek patosa je veliko: od slovite fraze »Čutim vašo bolečino« $\mathrm{v}$ predsedniški kampanji Billa Clintona do besed "Sem ljubeč človek" V političnih govorih Georgea W. Busha po 11. septembru; od diskurza upanja (»Yes, we can!«) in empatije Baraka Obame do republikanske "politike strahu" (utemeljeni na grožnji novega terorističnega napada ali prihajajoči recesiji) ter jezne retorike gibanja čajank; od emocionalizirane volilne retorike Donalda Trumpa, Marine Le Pen, Geerta Wildersa do strastne retorike kampanje za odhod iz EU pred referendumom o brexitu; od politike jeze, zamere in upanja $\mathrm{v}$ obdobju Trumpovega predsedovanja vse do "politike empatije« novoizvoljenega predsednika Johna Bidna. Igranje na emocije je značilno, tako znotraj rutinske kot volilne politike, tudi za slovenski prostor, posebej pri temah, kot so begunci, tujci in manjšine (npr. Dragoš, 2004; Pušnik, 2017). Politiki z uporabo diskurza emocij stremijo $\mathrm{k}$ izgradnji emocionalnih vezi z občinstvom (volilno bazo) ali priklicujejo emocionalne odzive, ki napeljujejo k prepričanjem, odločanju, vedenju in oblikam politične angažiranosti $\mathrm{v}$ duhu posredovanega emocionalnega sporočila.

Po Loseke (1993: 207; 2009) javni narativi in diskurzivne izjave vsebujejo in konstruirajo "želeno emocionalno orientiranost in odzive« ter moralno 
vrednotenje "tipov« ljudi. Politiki s spretno uporabo idej o tem, kako svet deluje, kako bi moral delovati in kakšne so pravice in odgovornosti ljudi v tem svetu (simbolne kode), ter idej o tem, katere emocije je primerno občutiti kdaj, kje in kako (emocionalne kode), izvabljajo ali priklicujejo specifične emocije, ki so ključnega pomena za doseganje političnih ciljev. Kot ugotavlja Reyes (2011: 789), politični diskurzi sprožajo emocionalna stanja, ki so »idealna za legitimiziranje poznejših političnih delovanj, osnovanih na učinkih teh emocij«. Emocije namreč vodijo in pripravijo občinstvo, da sprejme predloge in smeri delovanja akterjev, ki so te emocije prvotno vzbudili (ibid.: 790).

Politični diskurzi torej merijo tako na razumevanje in delovanje kot tudi na emocije državljanov (emocije so pravzaprav del »razumevanja«). Oblikujejo želene načine čutenja do določenih družbenih skupin, ki so zlasti v desnih populističnih tekstih - naslovljeni kot radikalno drugačni (Fortier, 2010; Richards, 2007). Ne predpisujejo le, kako naj se dober, legitimen državljan obnaša, ampak tudi kaj mora oz. je legitimno (ob)čutiti do določenih skupin. Tako izvabljene ali priklicane emocije državljanov politiki sočasno kanalizirajo v politično delovanje, skladno z interesi lastnih političnih strank ali drugih političnih in družbenih grupacij. Normativna 376 konstrukcija dobrih državljanov se tako odvija skozi posebno obliko vladnosti v Foucaultovem smislu, tj. skozi mehanizme "afektivne vladnosti« preko uporabe simbolnih in emocionalnih kod upravlja z javnimi in osebnimi emocijami/afekti ter oblikuje stališča in vedenje ljudi.

Levinger (2017) in Woodward (2002) ugotavljata, da sta izražanje in strateška uporaba emocij ključna dejavnika, ki pojasnjujeta privlačnost in prevlado določenih diskurzov. Uporaba emocij v politiki ima, kot kažejo raziskave (Escobar, 2011: 111; Schrock et al., 2017; Wirz, 2018), močan retorični potencial in povečuje učinkovitost političnega komuniciranja. Emocionalni odzivi na apele patosa so pomembni za različne oblike političnega uspeha: volilni uspeh, prevzem ali ohranitev oblasti, premik neke politične agende z obrobja v mainstream političnega diskurza (Levinger, 2017: 2-3), legitimizacijo političnih odločitev (Reyes, 2011), obračanje pozornosti od lastnega početja ali doseganje popularnosti. Bolj učinkovito retoriko izkazuje populistična politika (desnega krila) zaradi strastnega sloga komunikacije, medtem ko se opiranje na »tehnokratski slog« (Moffitt, 2016) pri »zmerni« politiki (iz)kaže kot manj učinkovito in manj medijsko privlačno (Schrock et al., 2017; Wirz, 2018; Abdell-Fadil, 2019: 17; Szabo, 2020: 7; Villadsen, 2020; Westen, 2007 v Hoggett, 2009: 56, 59). Levinger (2017) ugotavlja, da so bili močni emocionalni odzivi, ki jih je v volilcih vzbudila retorika strahu, jeze in ljubezni, ključni za nedavni volilni uspeh populističnih gibanj v ZDA, Združenem kraljestvu, Franciji in na Nizozemskem. 


\section{Ko ostanejo samo še emocije: diskurzivne strategije desnega populizma}

Emocionalizacija politične komunikacije ni inherentno »dobra" ali "slaba«, ampak je rezultat tega, v kakšnem »duhu«, kontekstu oz. s kakšnimi nameni in cilji politika uporablja emocionalni jezik. Politični akterji lahko svojo »strast« do skupnih zadev združujejo s komunikacijskimi in mobilizacijskimi strategijami za transformativne družbene povezave in konstruktivno razreševanje družbenih problemov. Lahko pa manipulirajo z emocijami in mobilizirajo razdruževalne strasti za ustvarjanje razklanih, (raz)druž(b)enih družb (neliberalna uporaba emocij). Progresivna politika je lahko načelna in obenem "strastna«, utemeljena je na tem, kar Hoggett (2009: 59) poimenuje "občutena premišljenost«. Brez strasti v politiki pravzaprav ni načelnosti. Strast daje političnim liberalcem moč za spoprijem z njihovimi neliberalnimi nasprotniki ter "pogum za odzivanje s sočutjem, ko je to primerno, in z agresijo, ko je to nujno« (Hoggett, 2009: 56).

»Strastno« politiko so v poznih sedemdesetih in osemdesetih letih 20. stoletja vpeljali novi politični igralci, ki so na politični trg vstopili organizirani v družbena gibanja (Frevert, 2019). Gibanja državljanov so razvila nov političen jezik, zaznamovan s terapevtsko kulturo (Furedi, 2004), ki je emocije povzdignila $\mathrm{v}$ osrednje sredstvo komunikacije tako $\mathrm{v}$ zasebni kot javni sferi. Družbena gibanja so izhajala iz osebnega, emocionalnega izkustva zatiranih skupin (pod geslom »Osebno je politično") in osebno pripoved uporabila kot osnovo za aktivizem. Gradila so solidarnost, entuziazem in samozavest kot podlago »emocionalne skupnosti« in kot vire moči za progresivne spremembe. Nov emocionalni jezik so pozneje posvojile politične stranke, ki so izšle iz vala neposredne demokracije in radikalne leve skupine, nato je lingvistične prakse patosa prevzel populizem (Frevert, 2019). V desnem populizmu je emocionalni jezik zapeljal v drugo smer - v razdruževanje, zaničevanje Drugih, krčenje politike na emocije (emotivizem), geslo »Osebno je politično« zamenja geslo »Politično je osebno«.

Populizem, ki prezentira družbo na podlagi antagonizma elita-ljudstvo, zavrača elito in glorificira ljudstvo, pripet na nacionalizem in nativizem pa prezentira in diskreditira tudi druge sovražnike ljudstva (tujce, begunce, manjšine). Politični slog populizma je prepoznaven $\mathrm{v}$ uporabi retorike strahu, jeze in sovraštva, s katero razvnema ljudi in stopnjuje emocionalne napetosti, ki jih generirajo prevladujoči neoliberalni diskurzivni, ekonomski in politični režimi. ${ }^{5}$ Odgovornost za družbene probleme vali na osovražene

5 Populizem ne kreira (kolektivnih) emocij "iz ničesar", ampak črpa iz emocionalne naelektrenosti v družbi. Zajema iz bazena emocij, ki se oblikuje kot rezultat družbenih in ekonomskih razmer neoliberalne globalizacije, ter iz stoletja ustaljenih stereotipov v politični kulturi (npr. rasizem, ksenofobija). V družbi razširjene negativne emocije (jezo, strah, tesnobo, negotovost, zamere, gnev, občutke prikrajšanosti) nezado- 
skupine, ki jih razmejuje od pravega ljudstva ali »avtentične nacionalne skupnosti (Levinger, 2017). Primer referiranja na slednjo oz. razmejevanja skupin ljudi najdemo $\mathrm{v}$ zapisu poslanca $\mathrm{v} D \mathrm{DZ}$, ki na blogu $\mathrm{v}$ povezavi $\mathrm{s}$ t.i. "prišleki iz t. i. balkanskih republik« zapiše, da na ulicah Ljubljane velikokrat "naletimo« na tujo govorico, in nadaljuje: »Pomisliš; verjetno so turisti, ali pa tudi ne. Nekateri ne znajo jezika države, ki jih hrani. [...] Iz navedenega se moramo tisti 'staroselci' slovenskega naroda vprašati, kaj smo delali narobe. [...].« Proti koncu zapisa preberemo še: »Sam sem zato, da damo Slovenijo spet Slovencem《 (Lenart, 2021). Populizem obvladuje miselnost, ki daje prednost mejam, fizičnim/prostorskim in kulturnim/simbolnim, Trumpov populizem je tu znova dober primer (omenimo zgolj predvolilno obljubo gradnje zidu na meji z Mehiko). Populistični diskurzi z retoriko okoli tem globalizacije, vdora migrantov in beguncev ipd. generirajo občutke ogroženosti in strahu. V kontekstu kroženja afektivnih podob beguncev kot ogrožajočih, nevarnih je razumeti tudi izjavo Janeza Janše, predsednika SDS, ki je v povezavi $\mathrm{z}$ »begunsko problematiko« $\mathrm{v}$ Sloveniji leta 2015 zagovarjal postavitev ograje na meji in jo v televizijskem intervjuju opredelil kot»[...] ograjo, ki brani svobodo. Je ograja, ki brani red [...] (v Luthar, 2017: 159). ${ }^{6}$ Ograja v imenu svobode »obljublja«ne le rešitev strahu pred tistimi, ki ogrožajo našo 378 svobodo (oz. svobodo od škode pred drugimi), ampak tudi zaščito reda. Konstrukcija oz. ohranjanje mej (reda, nadzora) se odvija skozi diskurzivno produkcijo in upravljanje emocij.

Emocionalna energija, ki jo generirajo populistične politike strahu, jeze in sovraštva, ni sila, ki "poziva na in odpira politično komunikacijo, ampak jo zapira. Emocije političnih odnosov ne gradijo, ampak jih zavirajo« (Frevert, 2019: 7). Retorika, ki jo je Trump uporabljal v času svojega predsedovanja, "ni promovirala razumevanja, ampak distanco, izolacijo in zavrnitev vsega, razen množice pred njim« (Clem, 2017: 11). Na množice pred njim, lojalne podpornike je Trump apeliral z retoriko ljubezni, intenca katere je bila krepitev emocionalnih vezi (Trumpovo ponavljajoče se sporočilo občinstvu: "I love you" (»Rad vas imam»)). Kot ugotavlja Levinger (2017: 2), je bilo prav obvladovanje konvencij »jezika ljubezni« en od ključnih dejavnikov Trumpovega političnega uspeha. Ljubezen je v Trumpovi politični retoriki delovala kot vezivno tkivo, ki utrjuje vezi med voditeljem in sledilci ter sočasno kot »velika izključevalka« drugih, drugačnih.

\footnotetext{
voljnih državljanov populizem artikulira in predeluje skozi politične diskurze tako, da se prilegajo njegovim političnim potrebam in ciljem. Ali po Hoggessu (2009: 104): politični diskurzi obstoječim emocijam podelijo pomen in s tem posebno obliko ter smer. Populizem je učinkovit, ker je družba že nekako pripravljena nanj.

6 Navajam celoten citat (Luthar, 2017: 159): "... J To ni ograja, kot je bil berlinski zid, ki je preprečeval, da bi šli ljudje iz Vzhodne Nemčije v svobodo, ampak je ograja, ki brani svobodo. Je ograja, ki brani red, je ograja, ki omogoča, da se obvlada množica brez nasilja. Druga možnost je samo uporaba nasilja, tega si pa nihče ne želi. [...].«.
} 
Po Frevert (2019) emocije ne služijo sodobni politiki, ampak jo ustvarjajo. Emocije so same po sebi pretvorjene v politični argument: »Način čustvovanja je osnova političnega delovanja, spodbuja in usmerja politiko, in to namerno. O emocijah se ni mogoče pogajati. Preprosto obstajajo. Tako vsaj pravijo«(2019: 6). Namesto o »emocionalizaciji politike« - v historičnem poteku vselej prisotnem pojavu - je zato ustrezneje govoriti o "politizaciji emocij«. V desnem populizmu so negativne emocije osrednji atribut, okoli katerega se oblikuje in na katerem je utemeljeno samo politično delovanje. Trump je bolj kot na ideološke volilce igral na strune jeznih volilcev: »Trumpov populizem deluje zaradi jeze, ki jo izraža: jeza je temelj njegovih apelov in njegovega političnega projekta" (Wahl-Jorgensen, 2019: 126). V času Busha (2001), kot smo že zapisali, je jeza postala resolucija, poslanstvo, trenutek (ko zablesti volja, afekt ljudstva). Političnost se torej ne izraža le skozi politične programe, ampak se oblikuje in izraža tudi skozi skupne emocije, ki jih artikulirajo diskurzi oz. skozi skupno emocionalno izkustvo. Po Abdell-Fadil (2019) »emocije utrjujejo politične ideje ali pa so sam material, iz katerega so oblikovane politične ideje«, so »sile, ki podžigajo proces drugačenja in zagotavljajo moralno upravičenje 'naše' nastrojenosti do 'drugih', s katero ščitimo sebe pred zaznano grožnjo uničenja« (Abdell-Fadil, 2019: 24).

Populizem, kot ugotavlja Arditi (2004: 137), izkorišča »napetost med demokratičnimi institucijami in odtujenostjo, ki jo te neizogibno ustvarjajo, oz. med romantičnostjo spontanega izražanja volje ljudstva na eni strani in na drugi institucij in profesionalne ekspertize, ki so potrebne, da to voljo predstavljajo«. Ali drugače, izkorišča inherenten potencial nezaupanja v demokracijah do odtujenih, skritih političnih sil, ki (da) zavajajo in odločajo v lastno korist namesto $v$ korist ljudstva. In prav v ozračju sumničavosti do posredniških institucij, tehnokratskih in odtujenih elit ter anonimnih birokratskih in tržnih mehanizmov se emocije in njihovo »spontano«, takojšnje izražanje populistom kažejo kot »pristna« politična reakcija, »naraven« odziv na »krizne razmere«.

Skozi populistično optiko se emocije dojemajo kot neposredne politične izjave, ki zaobidejo posredovanje in reprezentacije kompleksa institucij. Predstavljajo besedo in glas tistih, katerih volja in interesi so se v kompleksnem političnem sistemu izgubili. Ta utišani glas ljudstva si pogosto "prisvojijo « karizmatični voditelji in mu skušajo povrniti (afektivno) moč. Populisti »obljubljajo prekinitev birokratskih rutin in preobrazbo politike $\mathrm{v}$ bolj osebno izkustvo« (Arditi, 2004: 137). Ali v Trumpovem egocentričnem slogu: »[...] Jaz sem z vami, Američani. Jaz sem vaš glas. [...] Boril se bom za vas. [...] Rad vas imam« (Charteris-Black, 2018: 25). V mačističnem slogu prepričujejo, da so edini legitimni predstavniki ljudstva in edini, ki razumejo (čutijo) in resno jemljejo njegove skrbi, bolečine, strahove in upanje 
(populizem igra tudi na pozitivne, ne zgolj negativne emocije). Npr. Farage je z neposrednim in namerno pretiranim jezikom ustvaril javno osebnost, ki projicira poštenost in realizem ob soočenju s korupcijo in prevaro (Breeze, 2020). To je bila tudi persona, ki je spodbujala in "urila« nezadovoljne državljane za specifične načine doživljanja in izražanja emocij (Leezenberg, 2017: 269). S prilaščanjem monopola nad reprezentiranjem resničnih občutij in interesov običajnih ljudi populisti delegitimizirajo politične tekmece in izkazujejo svojo antipluralistično in antidemokratično držo.

Populisti, skratka, vidijo emocije kot »legitimen in zadosten vodnik za urejanje političnih vprašanj« in zavrnejo dejstva kot nepotrebna v političnem odločanju (Villadsen, 2020: 57). Mesto dejstev zasedejo emocije, o katerih se ni mogoče pogajati.

Vpeljava emocij kot suverenega principa v politični debati in sumničavost do dokazov, ki temeljijo na dejstvih (Villadsen, 2020: 58), vodi v neuravnoteženo mobilizacijo patosa, logosa in etosa. Ustvarja emotivizem, ki daje prednost: emocionalnim impulzom pred globljimi premisleki, emocionalnim gestam pred (vsebinskimi) informacijami, trenutnim zadovoljitvam pred konkretnimi rešitvami problemov, emocionalni trivialnosti pred substantivnimi vprašanji in vsebinsko razpravo. Wildersovi grobi, konfrontirajoči tviti ne puščajo nobenega prostora za razumske argumente (Leezenberg, 2017: 251), Faragejeve izjave niti niso informativne niti niso mnenja v običajnem smislu (Leezenberg, 2017: 269). Emotivizem se kaže tudi v značilni - (ne) premišljeni, (ne)pretehtani - takojšnosti Janševega komuniciranja: od tvita o »odsluženih prostitutkah", Johnu Bidenu kot enem izmed najšibkejših predsednikov v zgodovini (če bi bil izvoljen) do poobjave tvita o klofutah, ki »bi se lepo prilegle« eni od poslank. ${ }^{7}$ Podobno je funkcija zapisa poslanca DZ Jožefa Lenarta (2021) v zvezi s »socialnimi kulturniki - kulturnimi socialisti« (kot jih imenuje) zgolj ta, da zbode, zasmehuje, poniža: »[...] svoje zahteve pač izražajo na svoj način, ker verjamejo v svoje umetniške talente. [...] Menijo pa tudi: da imajo pravico do brezplačnih prostorov za svoje ustvarjanje, ki pa jih v nekaj letih po njihovi uporabi ni več mogoče uporabiti niti za hlev.« Emotivizem reducira zapletena policy vprašanja na binarnost »to je super - to je grozno«, torej na razvnemanje emocij, negativnih do Drugih, pozitivnih do lastne skupine. Populistični emotivizem namesto tehtnih argumentov, iskanja kompromisov in sodelovanja deluje $-\mathrm{z}$ negativno emocionalno retoriko, posredovano in stopnjevano skozi družbene medije, zlasti Twitter - izključevalno tako do določenih družbenih skupin kot do političnih nasprotnikov.

7 Seksistične tvite objavljajo ali poobjavljajo tudi drugi politiki iz desnega spektra (npr. tvit o leglu feministk na CSD-jih), so pa tudi leve provenience (npr. tvit J. P. Damijana o ministrici). 


\section{Teorija lepljivih emocij}

Za razumevanje diskurzivne konstruiranosti in performativne vloge emocij v oblikovanju identitet in kolektivov skozi diskurz je potreben premik v izhodišču razumevanja emocij. Konvencionalno razumevanje, po katerem so emocije subjektom inherentni pojavi, je nezadostno, saj predpostavlja akterja, ki je nepovezan s strukturnim kontekstom ter razmerji moči. Ahmed (2004a in 2004b) je razvila alternativen model emocij, ki nas preusmeri, prvič, od osredinjenosti izključno na emocije "V« posamezniku k njihovim kolektivnim dimenzijam, drugič, k razumevanju emocij kot, vsaj delno, diskurzivne družbene konstrukcije in tretjič, k emocionalnemu drugačenju v političnem in medijskem prostoru, prek katerega se ustvarjajo antagonistične relacije med »nami« in »njimi« ter družbeni in politični kolektivi.

Emocije so intencionalne, vselej se na nekaj nanašajo - na objekte ali subjekte, stvari, specifične situacije, ideje, prostore itd. Ali kot navaja Ahmed (Parkinson v Ahmed, 2004a: 7), so emocije "'o nečem': vključujejo smer ali orientacijo do objekta«. Orientacija emocij je povezana z odnosom subjekta do objekta, z oceno, presojo, vrednotno sodbo o objektu. ${ }^{8}$ Ti kognitivni procesi so pogojeni tako s subjektovimi zaznavami in preteklimi izkustvi kot tudi s kulturnim okvirom, znotraj katerega živi in je socializiran. Avtorica poudarja: »(...) biti na določen način emocionalno aktiviran v srečanju z drugim vključuje branje ne le srečanja, ampak tudi tega drugega kot nekoga, ki ima določene značilnosti« (poud. v orig., 2004: 28). Te interpretacije, ocene se izražajo v načinu, na katerega se telesa usmerjajo glede na druga telesa. Ocene uvedejo neko vrsto delovanja - obračajo nas »k« objektom/telesom (želja po bližini) in »stran« od njih (oddaljevanje, distanciranost) - ali aktivnosti v oz. s katero se emocije premikajo med telesi. "Emocije so relacijske: vsebujejo (re)akcije ali relacije 'k' ali 'stran' v odnosu do teh objektov« (Ahmed, 2004a: 8). Kraj izvora emocij ni subjektova duševnost, niso omejene na človeško telo. Nasprotno, pri emocijah gre vselej za gibanje: premikajo subjekte, ki se posledično gibajo v različnih smereh, odvisno od tega, kako so emocionalno aktivirani oz. izzvani, kakšne specifične emocije (ob) čutijo. Tako niso ne povsem znotraj (psihološke) ne povsem zunaj telesa (družbene), ${ }^{9}$ pač pa so sile, ki vplivajo na samo razlikovanje med "znotraj« in "zunaj« oz. začrtajo meje, ki to razliko definirajo: »ustvarjajo sam učinek na površinah ali mejah teles in svetov« (2004b: 117).

8 Naši emocionalni odzivi na objekt vsebujejo miselne procese, ki se odvijajo sočasno kot samo (ob) čutenje na ravni telesa (2004a: 6). Ahmed opisuje emocije kot preplet „občutkov telesnih sprememb", ki so rezultat stika z objekti oz. drugimi, in "branja "tega stika in drugih kot vzroka našega emocionalnega odziva.

9 V psihološkem modelu delujejo emocije od "znotraj navzven" (prihajajo iz posameznikove notranjosti, iz nagonov, najprej jih začutimo v telesu, potem se gibajo k objektom), v sociološkem modelu pa kot pri/sile, ki delujejo od "zunaj navznoter" (prihajajo iz družbe in se nato prenesejo "v"posameznika). 
Emocije vključujejo subjekte in objekte, a se ne nahajajo znotraj njih (2004a: 119). Niso »V« nas ali »V« objektih. Ne povzročijo jih objekti, ampak nastajajo kot rezultat našega stika z objektom (2004a: 6), in ta stik nas oblikuje v tem, »kdo smo« ${ }^{10}$ Emocije so relacijski pojavi, ki nastajajo v družbenih situacijah/srečanjih oz. družbeno-političnih interakcijah. Ali v jeziku avtorice, emocije krožijo med telesi: se gibljejo, premikajo, na nekatera telesa se "prilepijo« (Ahmed, 2004a: 4), prek drugih pa (z)drsijo (2004a: 8). Ne »bivajo V subjektih ali objektih", ampak "so producirane kot učinki cirkulacije (Ahmed, 2004a: 8). Izvor emocij torej niso objekti, na katere se usmerjajo, saj z njimi niso esencialno povezane, pač pa emocije oblikujejo objekt in so same oblikovane skozi stik z njim. Prav to, da niso pritrjene na subjekte ali objekte (Ahmed, 2004a: 128, 135), govori o tem, da se nahajajo in oblikujejo le v relaciji med subjektom in objektom. ${ }^{11}$ Potencial emocij, da potujejo - se prenašajo od enega do drugega posameznika - omogoča, da nas povezujejo in združujejo oz. generirajo površine kolektivnih teles.

Po Ahmed (2004a: 4) ključno vprašanje emocij ni, kaj so, ampak kako delujejo, kakšen je njihov učinek. Emocije v svojem kroženju »ustvarjajo stvari«, sebstvo, identitete in kolektive s tem, da zarisujejo meje, ki označujejo neko (skozi občuteno emocijo) zaznano razliko: med »menoj« in »drugim«, »menoj« in »nami«, »nami« in »njimi« ter z ohranjanjem teh binarnosti. Kot že omenjeno, niso »v« telesih, ampak »oblikujejo same površine teles, ki se izoblikujejo skozi ponavljanje delovanj $\mathrm{v}$ času in $\mathrm{z}$ usmerjenostjo ' $\mathrm{k}$ ' ali 'stran' od drugih" (2004a: 4). Površine in meje individualnih in kolektivnih teles nastajajo skozi načine našega odzivanja na objekte/druge (tj. občutenje emocij): »jaz« in »mi« sta oblikovana s stikom z objekti oz. drugimi (2004a: 1, 10). Emocije niso stranski produkt procesa formiranja identitet, ampak osrednji proces produkcije (političnih) identitet.

Emocionalno branje drugih vzpostavlja odnos, izkustvo odnosa pa ustvarja pomen in vrednost, izključevanje/vključevanje, pripadnost in predanost. Emocije (interpretacije drugih) torej povezujejo telesa s skupnostmi/kolektivi ali pa jih pozicionirajo zunaj njih. Kot zapiše avtorica, emocije povezujejo »nekatere subjekte z nekaterimi drugimi in zoper druge«

${ }^{10}$ Emocije oblikujejo svoje subjekte in objekte; npr. strah pred objektom (ocena, da je objekt nevaren, in spremljajoči telesni občutki) pridobi površino kot telo, ki je usmerjeno "stran od objekta, branje/interpretacija stika z objektom kot nevarnega (razumevanje objekta kot sstrašljivega ") pa identificira objekt kot vzrok subjektovega strahu. Subjekt postane prestrašen, objekt pa strašljiv ("ne-jaz"): pripisovanje »krivde" oz. strahu objektu (prestrašen sem, ker si strašljiv) je učinek srečanja, ki giblje subjekt „stran od objekta (2004a: 8; 2004a: 126-128).

11 Emocije ne naseljujejo posameznika in potem v njem pojenjajo, ampak se premikajo med ljudmi, krožijo skozi subjektove interakcije z drugimi subjekti, so gibajoča, a se tudi pritrdijo, npr. subjekt, ki ob srečanju z neko osebo občuti gnus, je lahko začasno "poln česa slabega", toda to "slabo"se "izloči in prilepi na objekt oz. telesa drugih (2004a: 104) - tako se konstituirajo gnusna telesa. 
(Ahmed, 2004a: 117). So sile, ki premikajo in umeščajo posameznike/skupine na obe strani družbeno konstruiranih meja ter signalizirajo pozicioniranost telesa v odnosu do meje. Ali kot pravi Ahmed, način, na katerega (ob) čutimo druge nas združuje v skupnost/kolektiv, ki se, paradoksalno, »oblikuje« samo kot učinek takšne združitve, skozi vtise, ki jih na nas naredijo drugi (2004a: 54). Emocije "združujejo posameznike s skupnostmi - ali telesen prostor $z$ družbenim prostorom - skozi samo intenzivnost svojih predanosti« (2004a: 119).

Emocije pa ne krožijo kot take, ampak se gibljejo skozi cirkulacijo objektov, na nekatere objekte se prilepijo. Ko obravnavamo emocije in odnose med telesi (kako se telesa premikajo), je treba opazovati tudi odnos med emocijami in reprezentacijami oz. podobami v javnih diskurzih ter tekstih, ki krožijo v javni domeni. Opazovati moramo, kako se emocije povezujejo z znaki oz. cirkulirajo skupaj z njimi in kako se pri stiku med tekstom in telesi (nami) ustvari »odtis«.

Po Ahmed se emocije stalno premikajo med subjekti, objekti, drugimi in znaki ter nastajajo kot učinki cirkulacije med objekti in znaki. En od učinkov njihovega cirkulacije med posamezniki in kolektivi, znaki in podobami je ta, da postanejo določeni znaki in objekti »lepljive površine« oz. "zasičeni z afektom». Ko emocije drsijo, »tečejo čez« objekte, se na nekatere objekte (telesa drugih) pritrdijo in jim podelijo pomen. Ti z afektom nasičeni objekti/telesa, postanejo lepljivi, potujejo in se ob stiku z našimi lastnimi telesi vtisnejo, prilepijo na nas in naša telesa se prilepijo nanje (tako producirajo nadaljnje »lepljive odnose). Ob stiku teksta in teles se ustvari učinek, ki pusti svojo sled (2004a: 6) ali vtis, repeticija teh (emocionalnih) vtisov pa ustvari oz. rezultira v lepljivosti. Lepljivost je "učinek zgodovine stikov med telesi, objekti in znaki« (Ahmed, 2004a: 90) in način vzpostavljanja odnosa subjekta do objekta/teles na osnovi definiranja in vrednotenja slednjih.

Z uporabo metafore »afektivna ekonomija Ahmed trdi, da emocije delujejo na ekonomski način - bolj ko objekti, znaki (in z njimi afekti, emocije) krožijo, bolj afektivni (intenzivni) postajajo. ${ }^{12}$ Objekti ne cirkulirajo znotraj ekonomskega trga, ampak skozi različne tekste - skozi spletne zapise, politične govore ali izjave političnih akterjev ter časopisna poročila. »To je, emocije delujejo kot oblika kapitala: afekt se ne nahaja v znaku ali blagu, ampak je produciran samo kot učinek svoje cirkulacije (...) med objekti in znaki (= akumulacija afektivne vrednosti v času) (...) bolj ko znaki cirkulirajo, bolj afektivni postajajo (Ahmed 2004b: 120). Na primer, ponavljanje besed "paki« in "črnuh" skozi daljše časovno obdobje je ustvarilo lepljiv pomen

12 Ahmed (2004b: 121) opozori, da je analogija z Marxovo analizo vrednostne forme omejena in da referenca ostaja bolj ali manj metaforična. 
teh besed, ki prispevajo k »sovražnemu govoru« in stimulirajo emocionalne odzive teles (Ahmed, 2004a: 59-60). ${ }^{13}$

Stik teles z različnimi teksti, ki posredujejo emocije oz. podobe, ki so »nasičene ali celo prepolne afektov« (2004a: 95), ustvarja sledi - emocionalnost tekstov (tekstualnih in verbalnih sporočil) se dobesedno vtisne ali prilepi na telesa in ustvarja učinke na njih, tj. vpliva na njihove lastne emocionalne odzive (tj. na naslovljene teme ali družbene skupine, o katerih je govora), prevaja te emocije v delovanje in spremeni njihovo površino. Ali drugače, posamezniki med katerimi krožijo emocije - generirane s teksti - prevzamejo in sprejmejo te emocije kot »moje« ali »naše«, s tem se telesa mobilizirajo ter oblikujejo "površine« individualnih in kolektivnih teles.

Emocija, ki jo občutimo kot odziv na ponavljajoče se besede, stavke, ideje, ne biva »V« nas, ampak »V« stiku med nami in besedo (narativom, tekstom), njena lepljivost je učinek, ki izhaja iz zgodovine stika. Kako nekaj (ob)čutimo ni preprosto stvar individualnih vtisov, ki se ustvarijo na novo v sedanjosti, ampak ta stik z nečim ali nekom »oblikujejo pretekle zgodovine stika" (Ahmed, 2004a: 7). Tako so lahko določena telesa dojeta kot bolj strašljiva (gnusna) kot druga. V tem smislu emocije kot medosebni pojavi niso samo neposredni, trenutni odzivi, ampak so »odvisni od preteklih inter384 pretacij, ki jih nismo nujno sami ustvarili« (Ahmed, 2004a: 171). Povezanost emocije z določenim znakom ali podobo nima izvora v psihi, je sled zgodovine, ki »ostaja živa v sedanjosti« (Ahmed, 2004b: 126). Naše zaznave drugih, emocionalne naravnanosti nanje in naše odnose z njimi so posredovani s »kulturno zgodovino in spomini«, ki nam dajejo utemeljena znanja o določenih skupinah ter s tem prepričljive razloge za določene emocionalne odzive nanje.

\section{Sklep}

Populizem in (skrajno) desni politični diskurzi, od antimigrantskih, antibegunskih, antiblaginjskih do antiekspertnih in drugih diskurzov, z anti-X-sentimenti delujejo na podlagi »aktiviranja vrednotno obremenjenih in emocionalno nabitih izjav in konceptov ter spremljajočih emocij« (Chilton, 2017, v Breeze, 2019: 26). Politična komunikacija, ki se naslovljencev »dotakne« na emocionalni ravni, je retorično prepričljivejša od emocionalno manj evokativnih diskurzov in pomembno določa politične odločitve posameznikov. V »dobi emocionalne politike« so pogosto uspešnejši tisti politični

13 Temnopoltega človeka, ki gre mimo, se ljudje ne ustrašijo zaradi njega samega, niti strah ne prihaja iz »belega telesa", ampak gre za strah, ki se prenaša med telesi in pritrdi na znak temnopoltega človeka na osnovi družbenih in historičnih konstrukcij. Posredi je torej repeticija stereotipov o temnopoltem človeku, ta repeticija pa generira drugega kot objekt strahu, ta strah potem prevzamejo ljudje kot svojega lastnega (2004b: 131). 
akterji, ki s strastno (negativno) politično retoriko učinkovito generirajo objekte (tarče) specifičnih emocij, vzbujajo in mobilizirajo intenzivno emocionalno odzivanje podpornikov ter stimulirajo povezovanje enako čutečih v (politični) kolektiv. Slednji je vselej pozicioniran v izključevalno razmerje z drugimi kolektivi - političnimi nasprotniki ali skupinami, ki ogrožajo njegove ideale, posest, obstoj.

Medtem ko je vloga emocij v oblikovanju politične subjektivitete $\mathrm{v}$ zadnjih desetletjih široko pripoznana, je ob tem pogrešati bolj sistematično teoretizacijo emocij, ki bi omogočila preučevanje njihove performativne vloge emocij, zlasti v (skrajno) desnih političnih diskurzih. Pri vprašanju, kako emocije delujejo in kakšni so njihovi politični učinki, je zato dobrodošla teorija S. Ahmed o krožečih, lepljivih emocijah. V sklepnem delu navajamo nekaj uvidov, ki nam jih prinašata družbeni model emocij in ideja lepljivosti, s posebnim poudarkom na diskurzivni cirkulaciji najbolj lepljive od vseh emocij - sovraštva.

Najprej, zavrnitev psihološkega modela, po katerem so emocije zasebna "last« subjekta, in njegova nadomestitev $\mathrm{z}$ relacijskim modelom odpreta nov pogled, ki pokaže, da v subjektih ni ničesar neločljivo sovražnega. Biti sovražen do koga ali česa ni nekaj, kar ljudje preprosto $s o$, kajti sovraštvo ne mobilizira posameznikov »od znotraj«, ampak je kulturno uokvirjeno oz. je diskurzivne narave. Pripisovanje emocionalne vrednosti drugim je družbeni, kulturni in diskurzivni proces. Sovraštvo ne sodi v nobenega posebnega posameznika ali skupino kot nekakšna statična lastnina, ampak je produciran skozi kroženje znakov. Politični diskurzi z uporabo določenih form naslavljanja, poimenovanja, argumentiranja in prepričevanja vzpostavljajo in obnavljajo rasistična, ksenofobna, homofobna in mizogina stališča. Sovraštvo se torej vselej kreira v kontekstu merjenja moči med (političnimi) skupinami in diskurzivnih bojev, ki izhajajo iz družbenih in (antagonističnih) političnih konfliktov znotraj danega družbenega konteksta. Posamezniki pa občutijo sovraštvo $\mathrm{v}$ svojih individualnih srečanjih $\mathrm{z}$ drugimi, v katerih »berejo« in prepoznajo te druge kot »vir grožnje«, »sovražnike«. Stiki z drugimi so lahko medosebni, če pa potekajo (bolj ali manj) samo prek medijev (danes bolj pogosti kraji stikov), postanejo ti drugi še lažje tarče sovražnosti, saj odpade možnost preverjanja predstav o tuji in lastni skupini.

Drugič, trditev, da emocije ne bivajo v objektih, razjasni, da različne tarče sovražnosti niso utelešenje osovraženosti, strašljivosti, gnusnost, da torej sami po sebi ne vzbujajo (niso vzrok) emocij pri subjektih. To, na kakšen način nas v stiku z drugimi emocije premikajo ( $k$ njim ali stran od njih), je odvisno od naše interpretacije stika in značilnosti drugih. Kot osovraženo, strašljivo, gnusno je neko telo ustvarjeno šele skozi cirkulacijo emocij v vsakdanjem jeziku politikov in drugih javnih akterjev, ki utemeljujejo razloge z obrazložitvami, da so določena telesa nekaj, česar se bojiš oz. kar (moreš 
in moraš) sovražiti. Rasistična ali ksenofobna retorika tako prepričujeta, da sta frustracija in sovraštvo do Drugih upravičena in da »ogroženi« s svojimi sovražnimi dejanji ravnajo prav. Bolj ko se ideje, podobe, argumenti sovražne retorike uporabljajo in ponavljajo, bolj emocionalno nabite postajajo, tem bolj se lepijo na telesa Drugih in stabilnejše negativne asociacije ustvarjajo z njimi.

Sovraštvo pa ne kroži "prosto«, ampak vzdolž že izoblikovanih kulturnih linij, kot so rasa, etnija, spol, spolna usmerjenost. Sovraštvo in strah se na nekatere družbene skupine lepita bolj kot na druge. Skozi tekste in govor populističnih strank ter grupacij s konservativnimi programi se strah in občutek »muslimanske invazije« lepita na telo muslimanskega migrantskega moškega (ženske) ali na prosilce azila, sovraštvo in gnus pa na telesa temnopoltnih oseb, žensk ali na telesa istospolno usmerjenih. Negativna emocionalna vrednost določenih družbenih teles, ki so krožila v preteklosti, krožijo še dandanes, kar odseva v lahkotnosti diskreditacij, pripisovanja pomanjkanja določenih sposobnosti, marginalizacije, izključevanja in drugih oblik odzivanja na njih.

Tretjič, skozi ponavljajoče se lepljenje določenih emocij na določene družbene skupine se odvijajo procesi, ki tvorijo kolektivna telesa. Skupna 386 sovražna občutja ob istih drugih (katerih bližina grozi z odvzemom, skrunitvijo, nadvlado, prevzemom mesta) ustvarjajo skupna razpoloženja in miselnost ter deluje kot vezivo, ki subjekte povezuje in spaja v skupnost/ kolektiv. Skozi emocionalno razločevanje med telesi (belimi-temnopoltimi, heteroseksualnimi-homoseksualnimi, delavnimi-lenimi), drugačnost, tujost oz. z definiranjem, kdo ne pripada, se formira »mi-skupnost«. S tem ko se emocionalno ovrednoti "zunanje«, se združi, izoblikuje "znotraj«. Sovraštvo "znotraj« pa je občuteno kot povzročeno s strani izključenih in hkrati kot pripadnost notranji skupini. Sovraštvo deluje »zoper« in premika »stran« od osovraženih ter leži v sami osnovi skupnosti, kohezije. Deluje tako, da skrbi, da se obe strani meja ne pomešata.

Privlačnost sovražne retorike in njena diskurzivna politična moč pa nista (samo) v negativni nastrojenosti do »drugih«.»Dobra«stran je v tem, da sovraštvo predstavlja kot pozitivno navezanost na »nas«, na to, kar je »naše«, kar ljubimo in kar »moramo«zavarovati pred grožnjo drugačnih. Desni populistični diskurzi in programi konservativnih skupin, ki se organizirajo okoli skupne ljubezni do otrok, družine, naroda, predstavljajo strast svoje sovražnosti v njeni pozitivni razsežnosti. Večjo prepričljivost in utemeljenost pridobijo šele s tem, ko se povežejo z ideali ljubezni. Emocijo/vrednoto torej, ki jo je najtežje napadati in najlažje idealizirati. Bolj kot (eksplicitno) na sovraštvo do »drugih« se zato sklicujejo na ljubezen do »svojih«: ljubezen do družine, domovine, naroda, boga. Sovražni diskurzi konstruirajo sovraštvo kot ljubezen, uporabo sovraštva pa kot obrambo pred nevarnostjo, ki grozi, 
da bo odvzela, kar je »naše«. Ljubezen je hrbtna stran sovraštva. Sovražna retorika, ki pravi »Skupaj sovražimo, in to sovraštvo nas združuje« (Ahmed, 2004b: 118), se dopolni (zamaskira) z jezikom ljubezni, ki sovraštvo do drugih zamenjuje z ljubeznijo do sebe: »Ker ljubimo, sovražimo, in to sovraštvo nas združuje« (Ahmed, 2004a: 43).

V povezavi z zastavljenimi raziskovalnimi vprašanji ugotavljamo dvoje. Prvič, emocije in afekti igrajo osrednjo vlogo v političnih diskurzih (desnega) populizma: oblikujejo in utrjujejo politična stališča, ustvarjajo vezi med političnimi voditelji in podporniki, legitimizirajo politične odločitve voditeljev, zarisujejo meje med "nami« in »njimi«, tvorijo in mobilizirajo (politične) kolektive oz., v celoti gledano, spodbujajo določene politične ideje, strategije in prakse. Populizem vprašanja, kot so migracije, varnost, nacionalna kultura in blaginja, oblikuje v jeziku emocij (strah, jeza in sovraštvo). Te negativne emocije, pripete na ideje in predstave o skupinah, "odgovornih za ta vprašanja, oz. probleme, povezane z njimi, pogosto vodijo v emotivizem, služijo zgolj trenutni zadovoljitvi impulzov (odobravanje, navdušenje podpornikov), polarizirajo politični prostor in utrjujejo družbene neenakosti. Drugič, teoretski model premikajočih se emocij S. Ahmed omogoča razumevanje delovanja in učinkov emocij v političnem diskurzu in omogoča nadaljnje interpretacije ter empirično raziskovanje realnih, živečih emocij/afektov kot dela širših diskurzivnih struktur. Uporaba tega edinstvenega modela razkrije, da se s ponavljajočim se lepljenjem določenih emocij na določena telesa skozi krožeče diskurze, z emocionalnim vrednotenjem (vredna-nevredna telesa), diskurzivno dinamiko sovraštva in ljubezni ter posledičnim občutenjem drugih družbenih teles nekateri subjekti povezujejo s prednostnimi pravicami ter »združujejo z nekaterimi drugimi in zoper nekatere druge«. Formiranje kolektivov je v svojem temelju bistveno afektivni/emocionalni proces.

\section{LITERATURA}

Abdel-Fadil, Mona (2019): The Politics of Affect: The Glue of Religious and Identity Conficts in Social Media. Journal of Religion Media and Digital Culture 8 (1): 11-34.

Ahmed, Sara (2004a): Cultural Politics of Emotions. New York: Routledge.

Ahmed, Sara (2004b): Affective Economies. Social Text 22 (2): 117-139.

Ahmed, Shamila (2015): The 'Emotionalization of the »War on terror«: Counterterrorism, Fear, Risk, Insecurity and Helplessness. Criminology \& Criminal Justice 15 (5): 545-560.

Arditi, Benjamín (2004): Populism as a Spectre of Democracy: A Response to Canovan. Political Studies 52: 135-143.

Heaney, Jonathan G. (2019): Emotion as Power: Capital and Strategy in the Field of Politics. Journal of Political Power 12 (2): 1-21. 
Barbalet, Jack M. (1998): Emotion, Social Theory, and Social Structure: A Macrosociological Approach. Cambridge, UK: Cambridge University Press.

Bargetz, Brigitte (2015): The Distribution of Emotions: Affective Politics of Emancipation. Hypatia 30 (3): 580-596.

Bassols, Margarida, Anna Cros in Anna M. Torrent (2013): Emotionalization in New Television Formats of Science Popularization. International Pragmatics 23 (4): 605-632.

Bleiker, Roland in Emma Hutchison (2008): Fear no more: Emotions and World Politics. Review of International Studies 34 (S1): 115-135.

Breeze, Ruth (2019): Emotion in politics: Affective Discursive Practices in UKIP and Labour. Discourse \& Society 30 (1): 24-43.

Breeze, Ruth (2020): Angry Tweets A Corpus-assisted Study of Anger in Populist Political Discourse. Journal of Language Aggression and Conflict 8 (1): 118-145.

Clem, C. Jameon (2017): Going with Your Gut: A Study of Affect, Satire, and Donald Trump in the 2016 Presidential Election. Virginia Polytechnic Institute and State University.

Clough, Patricia Ticineto in Jean O'Malley Halley (ur.) (2007): The Affective Turn: Theorizing the Social, Durham: Duke University Press.

Dragoš, Srečo (2004): Islamofobija na Slovenskem. V: Roman Kuhar, Sabina Autar, Tomaž Trplan (ur), Poročilo skupine za spremljanje nestrpnosti 3: 10-27. Ljubljana: Mirovni inštitut.

Engelken-Jorge, Marcos, Pedro Ibarra, Güell Carmelo in Moreno del Río (ur) (2011): Politics and Emotions The Obama Phenomenon. VS Verlag.

Ernst, Nicole, Sven Engesser, Florin Büchel, Sina Blassnig in Frank Esser (2017): Extreme Parties and Populism: An Analysis of Facebook and Twitter across Six Countries. Information, Communication \& Society 20 (9): 1347-1364.

Escobar, Oliver (2011): Suspeding Disbelief: Obama and the Role of Emotions. V: Engelken-Jorge Marcos (ur.), Pedro Ibarra (ur.), Güell Carmelo (ur.) in Moreno del Río (ur) (2011): Politics and Emotions, 109-128, The Obama Phenomenon. VS Verlag.

Feigenson, N. R (2003): Emotions, Risk Perceptions and Blaming in 9/11 Cases. Brooklyn Law Review 68 (4): 959-1001.

Fortier, Anne-Marie (2010): Proximity by Design? Affective Citizenship and the Management of Unease. Citizenship Studies 14 (1): 17-30.

Frevert, Ute (2019): Emotional Politics, Den Haag, Januar 24: 1-7. Dostopno prek file://C:/Users/sadlz/Downloads/ute-frevert-emotional-politics-wrr-lecture-2019\%20(2).pdf, 12. 3. 2021.

Frijda NH, Manstead ASR and Bem S. (2000): The influence of Emotions on beliefs. V: Frijda NH, Manstead ASR and Bem S (ur.), Emotions and Beliefs: How Feelings Influence Thoughts, 144-170. Cambridge: Cambridge University Press.

Furedi, Frank (2003): Therapy Culture: Cultivating Vulnerability in an Uncertain Age. London: Routledge.

Goodwin, Jeff, James M. Jasper in Francesa Polletta (2001): Passionate Politics: Emotions and Social Movements. Chicago, IL: The University of Chicago Press. 
Hall, Cheryl (2007): Recognizing the Passion in Deliberation: Towards a more Democratic Theory of Deliberative Democracy. Hypatia 22 (4): 81-95.

Hoggett, Paul (2009): Politics, Identity and Emotion. NY: Routledge.

Irvine, Janice M. (2007): Transient Feelings: Sex Panic and the Politics of Emotions. GLQ 14 (1): 1-40.

Izard CE (2007): Basic Emotions, Natural Kinds, Emotion Schemas, and a New Paradigm. Association for Psychological Science 2 (3): 260-280.

Jasper, James M. (1998): The Emotions of Protest: Affective and Reactive Emotions in and around Social Movements. Sociological Forum 13 (3): 397-424.

Leezenberg, Michiel (2017): »Discursive Violence and Responsibility: Notes on the Pragmatics of Dutch Populism." V: Monika Kopytowska(ur.), Contemporary Discourses of Hate and Radicalism across Space and Genres, 243270. Amsterdam/Philadelphia: John Benjamins. Dostopno prek https://doi. org/10.1075/bct.93.09lee, 12. 12. 2020.

Levinger, Matthew (2017): Love, Fear, Anger: The Emotional Arc of Populist Rhetoric. Narrative and Conflict: Explorations in Theory and Practice 6 (1): 1-21.

Linjakumpu, Aini M. Helena (2007): Emotional Motivations of Islamic Activism Autobiographies and Personal Engagement in Political Action. Journal of Religion \& Society 19: 1-21.

Loseke, Donileen R. (1993): Constructing Conditions, People, Morality, and Emotion: Expanding the Agenda of Constructionism. V: Gale Miller in James A. Holstein (ur.), Constructionist Controversies, 207-16, New York: Aldine de Gruyter.

Loseke, Donileen R. (2009): Examining Emotion as Discourse: Emotion Codes and Presidential Speeches Justifying War. The Sociological Quarterly 50 (3): 497524.

Luthar, Breda (2017): Begunci in »Odmevi«: Epistemologija konvencij. Dve Domovini/Two Homelands 45: 153-168.

Mekina, Borut (2004): Izbrisani, prvi polčas: Odločna zmaga resnice. V: Roman Kuhar, Sabina Autar, Tomaž Trplan (ur), Poročilo skupine za spremljanje nestrpnosti 3: 56-70. Ljubljana: Mirovni inštitut.

Mottiff, Benjamin (2016): The Global Rise of Populism: Performance, Political Style, and Representation. Stanford, CA: Stanford University Press.

Ost, David (2004): Politics as the Mobilization of Anger Emotions in Movements and in Power. European Journal of Social Theory 7 (2): 229-244.

Pušnik, Maruša (2007): Dinamika novičarskega diskurza populizma in ekstremizma: moralne zgodbe o beguncih. Dve Domovini/Two Homelands 45: 137-152.

Richards, Barry (2004): The Emotional Deficit in Political Communication. Political Communication 21 (3): 339-352.

Reyes, Antonio (2011): Strategies of Legitimization in Political Discourse: From Words to Actions. Discourse \& Society 22 (6) 781-807.

Richards, Barry (2007): Emotional Governance: Politics, Media and Terror. Springer. Rosaldo Michelle Z. (1984): Toward an Anthropology of Self and Feeling. V: Richard A. Shweder (ur.) in Robert A. LeVine (ur), Culture Theory: Essays on Mind, Self, and Emotion, 137-157. Cambridge, UK: Cambridge University Press. 
Schrock, Douglas, Benjamin Dowd-Arrow, Kristen Erichsen, Haley Gentile in Pierce Dignam (2017): The Emotional Politics of Making America Great Again: Trump's Working Class Appeals. Journal of Working-Class Studies 2 (1): 5-22.

Sonntag, Albrecht (2011): False Expectations: The Counterproductive Side Effects of the EU's use of Political Symbols. V: Sonia Lucarelli (ur.), Furio Cerutti (ur.) in Vivien Ann Schmidt (ur.), Debating Political Identity and Legitimacy in the European Union. London, 115-130. NY: Routledge.

Szanto, T. in J. Slaby (2020): Political Emotions. V: T. Szanto (ur.) in H. Landweer (ur.), The Routledge Handbook of Phenomenology of Emotions, 478-492. Routledge.

Tettegah, Sharon Y. (ur.) (2016): Emotions, Technology, and Social Media. Amsterdam, The Netherlands: Elsevier.

Villadsen, Lisa, S. (2020): Emotions in Politics: Populism's Win? WCSA SPRING 1 (1): $57-72$.

Wahl-Jorgensen, Karin (2019): Emotions, Media and Politics. John Wiley \& Sons

Westberg, Gustav (2021): Affect as a Multimodal Practice. Multimodality \& Society 1 (1): 20-38.

Wirz, Dominique S. (2018): Persuasion Through Emotion? An Experimental Test of the Emotion-Eliciting Nature of Populist Communication. International Journal of Communication 12: 1114-1138.

Woodward, Kathleen (2002): Calculating Compassion. Indiana Law Journal 77 (2), Article 2. Dostopno prek https://www.repository.law.indiana.edu/ilj/vol77/ iss $2 / 2,13.3 .2021$.

Wouters, Cas (1986): Formalization and Informalization: Changing Tension Balances in Civilizing processes. Theory Culture and Society 3 (2): 1-35.

\section{SOURCES}

Bush, George W. (2001): Address to a Joint Session of Congress and the American People, 20 September 2001. Dostopno prek https://georgewbush-whitehouse. archives.gov/news/releases/2001/09/20010920-8.html, 7. 4. 2021.

Hutchison, Emma (2018): Why Study Emotions in International Relations? Dostopno prek https://isnblog.ethz.ch/international-relations/why-study-emotionsin-international-relations, 13. 4. 2021.

Lenart, Jožef (2021): »Ali si prebivalci Slovenije sploh še želimo biti Slovenci?« Sam kot poslanec DZ RS trdim: Ne sme nas biti strah ali pa sram, da bi povsod ponosno pokazali, da smo Slovenci. Dostopno prek https://www.sds.si/blog/ali-siprebivalci-slovenije-sploh-se-zelimo-biti-slovenci-sam-kot-poslanec-dz-rs-trdimne-sme, 29. 5. 2021. 